\title{
Article \\ eHealth-engagement on Facebook during COVID-19: simplistic computational data analysis
}

\author{
Caroll Hermann ${ }^{1^{*}}$, Melanie Govender ${ }^{2}$
}

1 Department of Psychology, University of Zululand, South Africa, hermannc@unizulu.ac.za

2 Department of Psychology, University of Zululand, South Africa, govenderm@unizulu.ac.za

* Correspondence: hermannc@unizulu.ac.za; Tel.: +27 359026607

\begin{abstract}
Understanding social media networks and group interactions are crucial to the advancement of linguistic and cultural behaviour. This includes the manner in which people accessed advice on health, especially during the global lockdown periods. Some people turned to social media to access information on health where most activities were curtailed with isolation rules, especially for older generations. Facebook public pages, groups and verified profiles, using "senior citizen health", "older generations", and "healthy living" keywords were analysed over a 12-month period to analyse the engagement promoting good mental health. CrowdTangle was used to source English language status updates, photo and video sharing information which resulted in an initial 116,321 posts and $6,462,065$ interactions Data analysis and visualisation were used to explore large datasets, including natural language processing for "Message" content discovery, word frequency and correlational analysis and co-word clustering. Preliminary results indicate strong links to healthy aging information shared on social media which showed correlations to global daily confirmed case and daily death totals. The results can be used to identify public concerns early on and address mental health issues in the senior generation on Facebook.
\end{abstract}

Keywords: social media, netnography, mental health, natural language processing, visualization, data analysis, COVID-19.

\section{Introduction}

This study aimed to investigate how social media users viewed health advice on Facebook Pages and Groups from 1 October 2020 to 30 September 2021 during the global COVID-19 pandemic. The aim of the study was to how how users engaged, what their sentiments were and if any themes were detectable from the content of messages. Ultimately, social media can be considered to reach large groups of people and spread content on health issues.

A fluid social media definition is a center of social groups (or community) networks that initiate conversations and enable relationships to form [1]. It can also take on a creative role or that of information sharing [1,2]. Freberg [3, p.772] claims that social media is used to "engage, reach, persuade and target specific audiences across multiple platforms". Social media can also be used to gain insight into how behaviours in communities happen at any given time [1] and traditional methods in research can "test and evaluate" [p.54] the substantial unstructured data obtained on online. Freberg [1] also proclaims growing expectations to make sense of online data. This study investigated how people engage in healthy and active aging activities through participation in Facebook groups, pages and verified profiles through reactions, shares and followers, etc.

Facebook, as the largest social media platform [1], was chosen as the platform to investigate how senior users' engage with pages, and groups on health during the COVID19 lockdown periods from October 2020 to September 2021. Facebook claims to have 2,9 
billion active users of which CrowdTangle tracks public content over 7 million Facebook pages, and groups [4]. Due to the ease of accessibility through CrowdTangle, Facebook was chosen over other social media platforms.

Since the arrival of social media (Facebook), people increasingly rely on social media and the internet to be informed on current affairs, issues of health, social activities, hobbies, etc. A recent study in Canada found that nearly $80 \%$ of users between the ages of 15 and 34 rely entirely on social media for news and current affairs [5]. Facebook was designed for adults with enabling maximum network reach [6] and as such, has become an important tool for businesses and researchers.

A 2017 study reported that $84 \%$ of Fortune 500 companies have a Facebook page [7]. Social media platforms are often used by groups for a specific community (such as "Healthy Living Group") whose main purpose is to educate. By using social media strategically, aiming content at a particular audience, much information can be disseminated as well as collected [1]. Audiences, relationships, personalities, content, actions and innovativeness became very important during the COVID-19 lockdown stages globally [1].

Posts, especially those regarding health, became of cardinal importance during lockdown. For many people, social media was the only means of communication during the global isolation stages. Online behaviour increased globally during the pandemic [8] and can be a valuable field of information.

Facebook reactions, include "Likes", "Wow", "Love", and "Haha", (grouped as "Total Positive" reactions) and "Sad" or "Angry" (grouped as "Total Negative" reactions). It has always been a question of how much credibility one can assign to "Likes" [7,9] and La France [9], claims that reactions were designed to "blunt-force emotional reaction", (p.19), by the click of a button and Lee et.al, [10] feel that "Likes" have the ability to drive traffic and serves a socialization component, but admit that the connotation can have variations. These reactions, including "sharing" behaviour, pose social risks. Praet, et al., [11] feel that reactions on social media serves to be mere "echo-chambers" (p.3).

Netnography has also evolved during the pandemic. Historically it gives users a lens or an opportunity to address cultural, health or other burning issues and when applied to the common good, can bring about change [12]. Netnography studies the online interactions between individuals through internet connections or computer-mediated communications [13]. These communications bind the user with more than just transmission of information but also ties people through a "common interactional format, location or 'space', ...or virtual 'cyberspace' (p.16).

This manuscript investigated older generations' health seeking behaviour on Facebook with regards to active aging. The term "active aging" is considered to be a process of "optimizing opportunities for health, participation and security in order to enhance quality of life and well-being" [14]. Most countries have policies to encourage people to work as they grow older and to delay chronic illnesses that are costly to the state and healthcare systems. Participation includes active involvement in the labour force, be it socially, economically, cultural or spiritual. time spent on social media significantly increased during this time as most people work from home and spend their time online.

Data visualization and storytelling were used to illustrate how groups and pages on Facebook were used to seek information. In many instances data is digitalized to further analyze data and trends [8,9]. Data visualization and effective communication thereof can turn insights into action [17]. Recently, digital storytelling gained popularity amongst researchers in the field on Humanities. Communicating information using storytelling forms a crucial instrument to effective communication [10]. 


\section{Materials and Methods}

Two strategies are employed when collecting online data: systematic collection via various platforms or third party software; and systematic organization of raw data analysis of organized data [1].This study employed third party software to collect social media updates on Facebook groups and pages.

CrowdTangle was used with search words "senior citizen health", "older generation" and "healthy living", resulting in 6462065 interactions with 116321 posts on public Facebook pages and groups in the English language from 1 October 2020 to 30 September 2021. COVID-19 data was obtained from John Hopkins University Dashboard [18].

Facebook Groups searches resulted in 3113 interactions from 294 posts and Facebook Pages resulted in 62758 interactions from 896 posts. The second phase of handling data involved cleaning of CrowTangle .csv files. Excel spreadsheets were prepared by combining social media and COVID 19 [15] data for the period 1 October 2020 to 30 September 2021. Ultimately, three sets of data were prepared, i) combination of COVID-19 statistics and Facebook "Likes at Posting" and "Followers at Posting", ii) Facebook Pages and Groups cleaned and iii) "Messages" to allow for easier computations. Columns in Facebook data, not essential to this study, such as identifiable information, as "User_Name”; "Facebook ID”, "Page Description”, "Date Page Created", "Post Created with Date and time", (only "Post Created Date" was retained and name changed to "Date"), "Post created Time", "Video Share Status", "Is Video Owner?", "Post Views" , "Total Views", "Total Views for All Cross Posts", "Video Length", "URL", "Link”, "Final Link", "Image Text”, "Description", "Sponsor ID”, "Sponsor Name”, "Sponsor Category", were removed as it was deemed not important to this study. OpenRefine 3.4.1 was used to remove trailing and leading white spaces and to change all data in the "Message" column to lower case and text for easier manipulation in Python 3. Data was further prepared by simplifying column names and removing duplicated columns, such as "Date" in both datasets. Data was filtered according to page categories and nonhealth categories were removed and cleaned of spam and advertisements, 27899 entries remained. All text in "Messages were transformed to lowercase, white spaces removed and transformed to "text" using OpenRefine. All "NaN" and missing values were removed.

\section{Analyses:}

The combined dataset was cleaned using OpenRefine, and Python 3 was used for content analysis, visualization and data analyses in most cases, using Matplotlib, Seaborn, Plotly and TextBlob. Both cleaned datasets were imported to a workbook in Jupyter Notebook.

Both datasets were described to indicate mean and standard deviation as well as distribution and correlation. Summaries of total COVID-19 infections, daily rates, cumulative deaths, daily deaths, likes and followers of postings, types of posts, page administrators' country of origin and page categories were plotted to give visual overview of data. A histogram and probability were plotted against new cases. Page and Group administrators top 10 countries were determined, top 10 Page Categories and Types were differentiated. The top 10 pages with the most posts were also identified. Finally, the messages (which included status updates and titles of photos or videos) were analysed for sentiment polarity, message length, word count, top 10 bigram and trigram words were identified, excluding stopwords. Words were tagged and analysed, as well as bivariate analysis performed. Finally, topic modeling was performed and presented schematically using Latent Dirichlet Allocation (LDA) in GenSim. 
Ethical mining of social media protocols was strictly adhered to. The study was registered with the University of Zululand Research Ethics Committee (UZREC 171110-030 Dept. 2021/1) and all identifying information has been removed from the raw dataset.

\section{Results}

\section{Descriptive analysis}

Of the total data obtained from CrowdTangle [19], 696 unique posts were identified. Concatenated dataset comprising of Facebook pages and groups and WHO COVID-19 Daywise [18] numbers, resulted in a total of 28948 rows and 28 columns of data.

Dataset 1 [11] contained 365 (from 1 October 2020 to 30 September 2021) rows of information in 6 columns, arranged by Confirmed COVID-19 cases, Confirmed Deaths, New Cases, News Deaths, and Number of Countries.

Fig. 1 depicts the trends of new COVID-19 infections and deaths grouped by month over a 12-month period and it is clear that there is a clear relationship between deaths and infections. As infections rose, so did deaths.

Figure 1: COVID-19 Monthly New Infections and DeathsFig. 1: Graphic presentation of

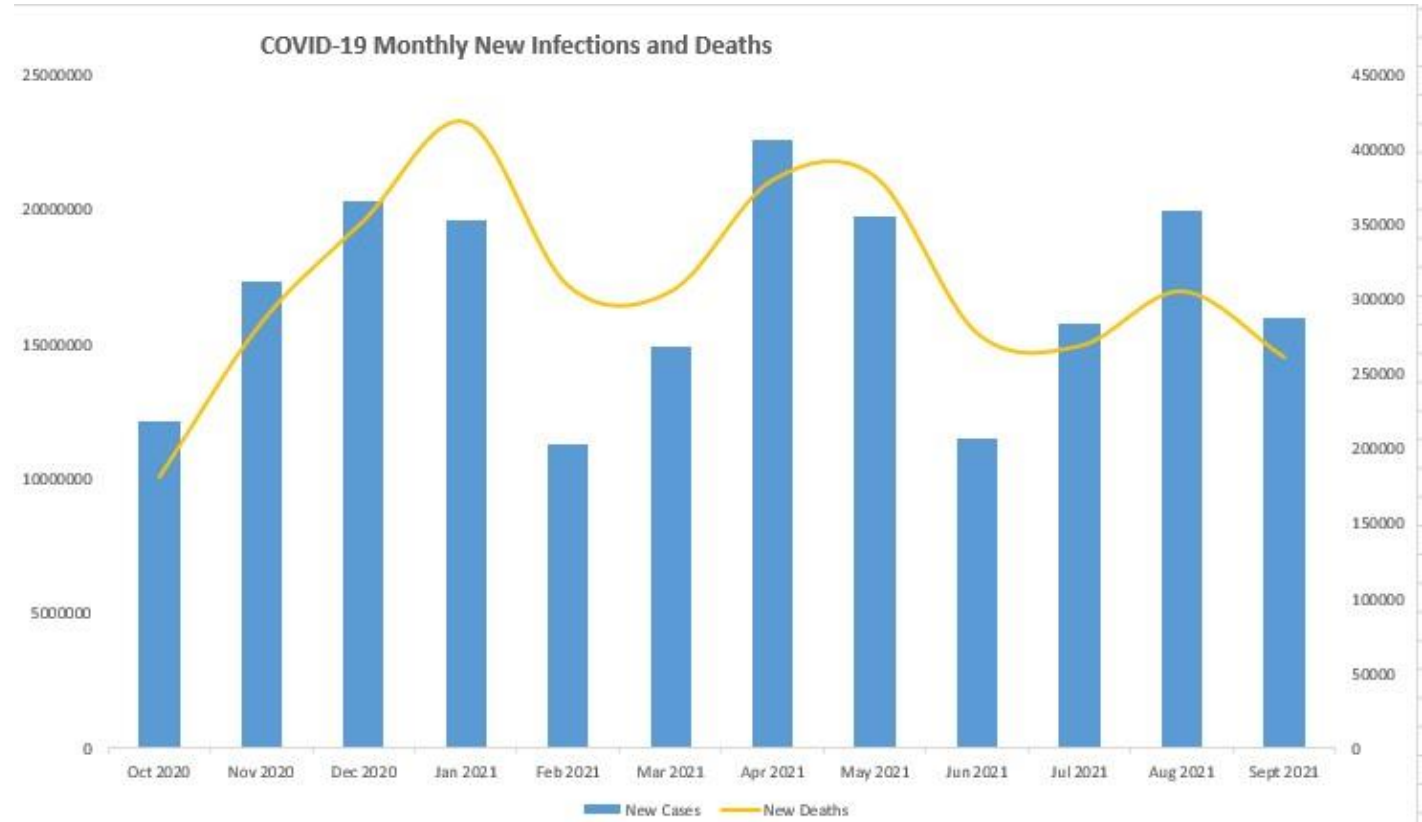

monthly new infections of COVID-19 and monthly new deaths for the period October 2020 to September 2021.

Table 1 summarises the descriptive statistics of Dataset 1 and 2. Dataset 1 based on the cumulative infections, deaths and daily new infections and deaths.

Table 1: Combined Datasets 1 and 2

\begin{tabular}{|l|r|r|r|r|r|}
\hline Description & \multicolumn{5}{|c|}{ Descriptive Statistics } \\
\hline & \multicolumn{1}{|c|}{ Total } & \multicolumn{1}{|c|}{ Mean } & \multicolumn{1}{l|}{ SD } & \multicolumn{1}{c|}{ Maximum } & Minimum \\
\hline Cumulative Infections & 48674562820 & 133354966.6 & 58988027.8 & 23344208971 & 34330972 \\
\hline Cumulative Deaths & 1067685110 & 29225164.7 & 1145757.8 & 4784857 & 1073081 \\
\hline New Infections & 200740517 & 549974 & 156158.1 & 1503571 & 260298 \\
\hline
\end{tabular}




\begin{tabular}{|l|r|r|r|r|r|}
\hline New Deaths & 3720389 & 10192.8 & 2991.8 & 20759 & 3630 \\
\hline Likes at Posting & 5317206337,00 & 206279,00 & 19336889.6 & 117508790,00 & 2,00 \\
\hline Followers at Posting & 5829532135,00 & 227597.2 & 2225409,00 & 117750435,00 & 2,00 \\
\hline Likes & 1815171,00 & 63.1 & 2863.4 & 4755906,00 & 0,00 \\
\hline Comments & 187810,00 & 6.6 & 93.9 & 7088,00 & 0,00 \\
\hline Shares & 335878,00 & 11.7 & 208.2 & 24162,00 & 0,00 \\
\hline Love & 253075,00 & 8.9 & 146.9 & 12376,00 & 0,00 \\
\hline Wow & 20730,00 & 0.7 & 24.2 & 2725,00 & 0,00 \\
\hline Haha & 107333,00 & 3.7 & 177.4 & 25048,00 & 0,00 \\
\hline Sad & 17452,00 & 0.6 & 30.2 & 3849,00 & 0,00 \\
\hline Angry & 6301,00 & 0.2 & 11.5 & 1816,00 & 0,00 \\
\hline Care & 43446,00 & 1.5 & 77.1 & 10193,00 & 0,00 \\
\hline Total Positive & 2132422,00 & 74.2 & 2929.2 & 482661,00 & 0,00 \\
\hline Total Negative & 23753,00 & 0.8 & 35.3 & 3893,00 & 0,00 \\
\hline
\end{tabular}

Table1: Descriptive Summary Analysis of COVID-19 Global Statistics - Datasets 1 and 2.

Dataset 2 [12] contained 28948 rows of information in 21 columns of clean data. Table 2 depicts the descriptive statistics of Dataset 2 based on Facebook Pages and Groups over a 12month period on health and aging. It describes the number of likes and followers at postings, various reactions, such as likes, love and wow emoticons. The "Total Positive" include all the positive reactions, excluding "Sad" and "Angry", as these were grouped under "Total Negative".

The researchers attempted to see if a noticeable trend existed between "Followers at Posting", "Likes at Posting", the number of "Comments" made on posts, as well as the "Total Positive" and Total Negative" reactions based on the fluctuating COVID-19 daily figures. Based on Fig 2 below, there is little evidence of a relationship between these variables.

\section{Figure 2: Reactions on Posts}

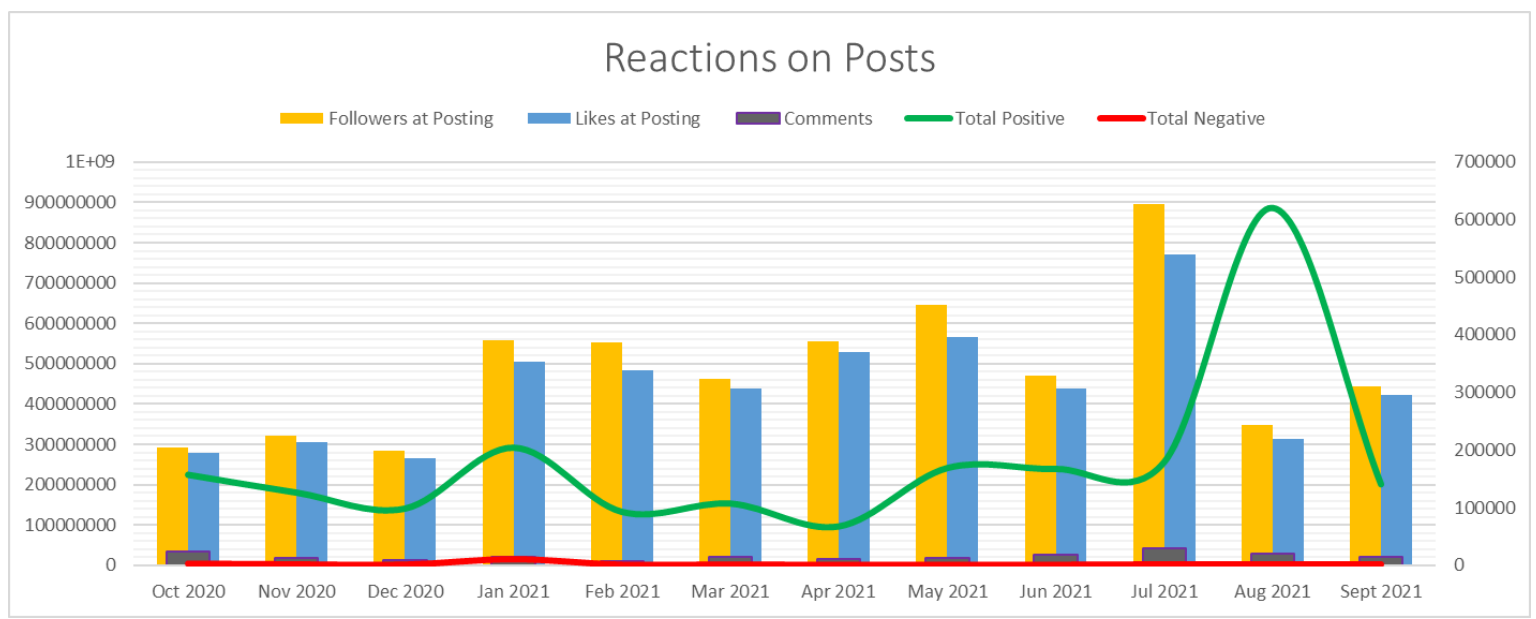

Fig. 2: Digital representation of reactions on messages on Facebook Pages and Groups 
Reactions on health posts increased slowly whereas negative sentiments decreased over time as based in Fig. 3.

Figure 3: Total Positive Reactions vs Total Negative Reactions

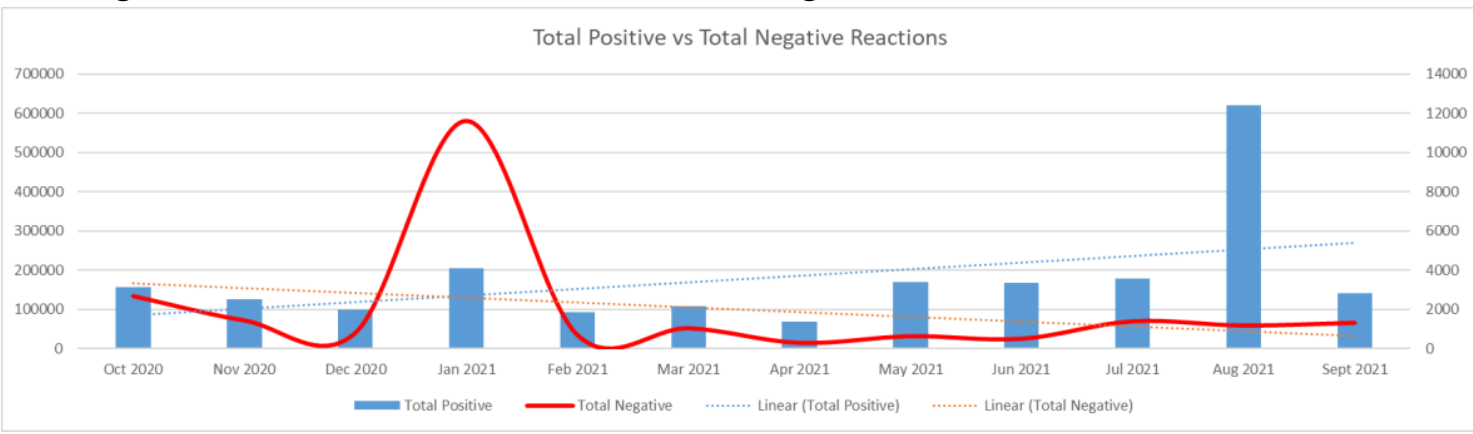

Fig 3: Total positive reactions vs total negative reaction on Facebook Pages and Groups message posts with trend lines.

\section{Figure 4: Daily New COVID-19 Cases vs Likes and Followers}

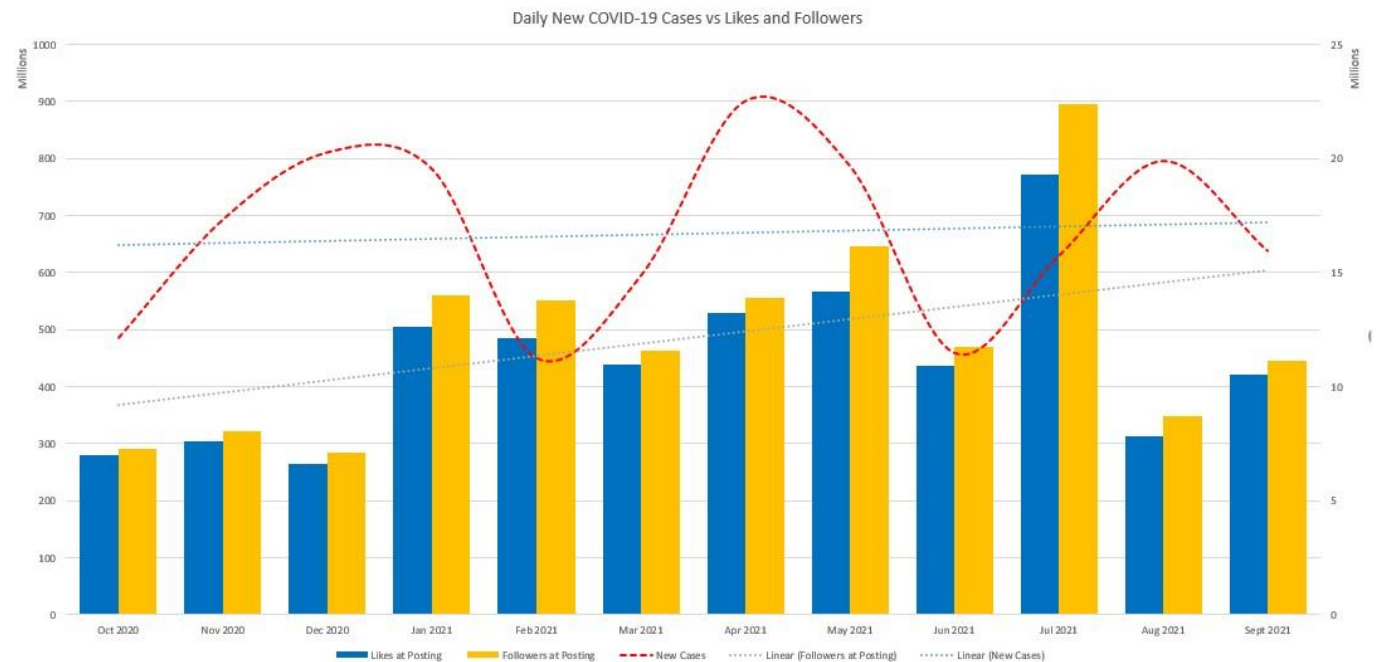

Fig 4: Depiction of New cases, likes and followers at posting with trend line

Facebook allows posts as status updates, links, photos, native videos, live videos complete and scheduled, videos and YouTube clips as posts. Fig.5 below that photo posts were in the majority $(18,722)$ and scheduled live videos (42) the least. 
Figure 5: Types of Posts

Types of Posts

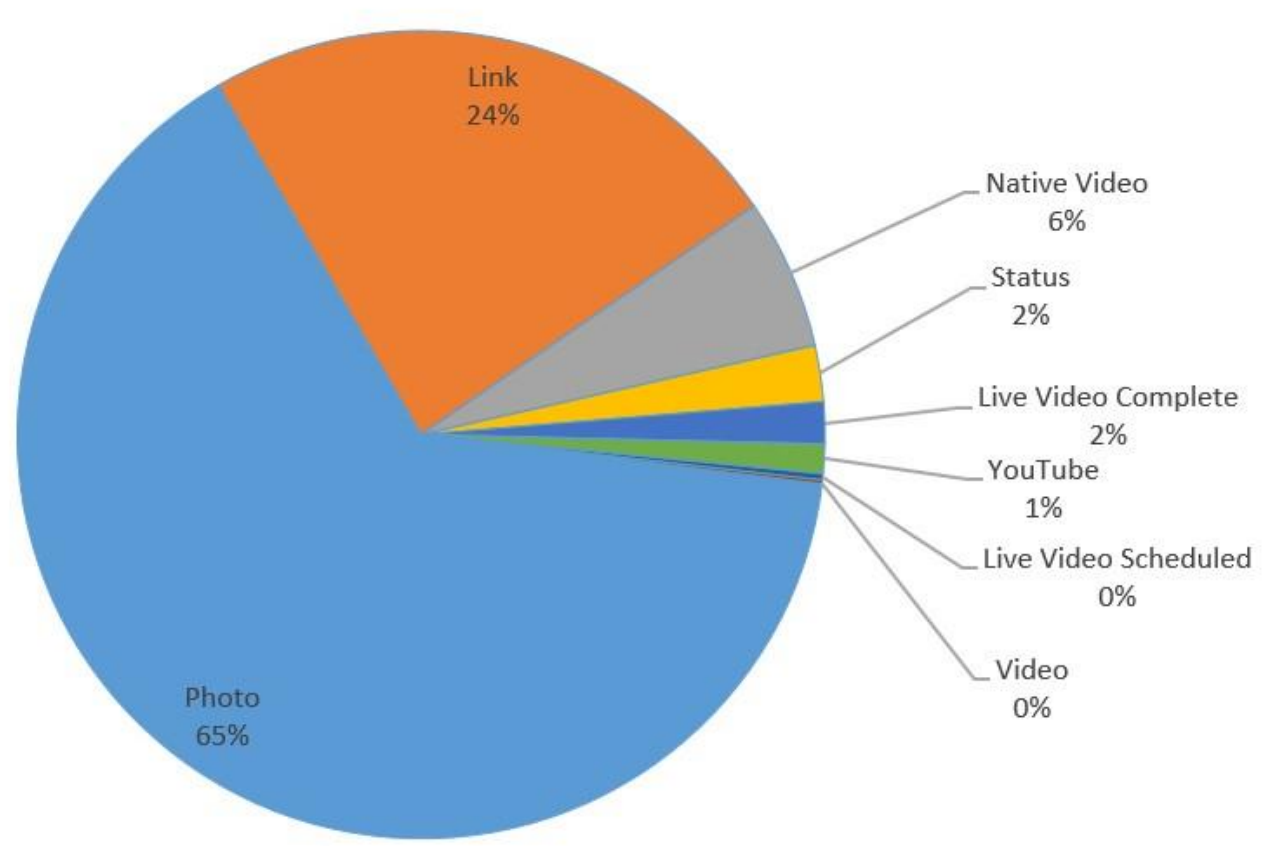

Fig. 5: Types of posts on Facebook Pages and Groups

Most pages and groups had Administrators that originated from specific countries. A total of 128 countries were represented in the dataset with the USA having the most administrators $(16,247$ or $27 \%)$, India $(1,976$ or $21 \%$ ) and Canada $(1,515$ or $18 \%$ ) in the top 3 . Fig. 6 represents the top 10 countries represented by page and group administrators. 


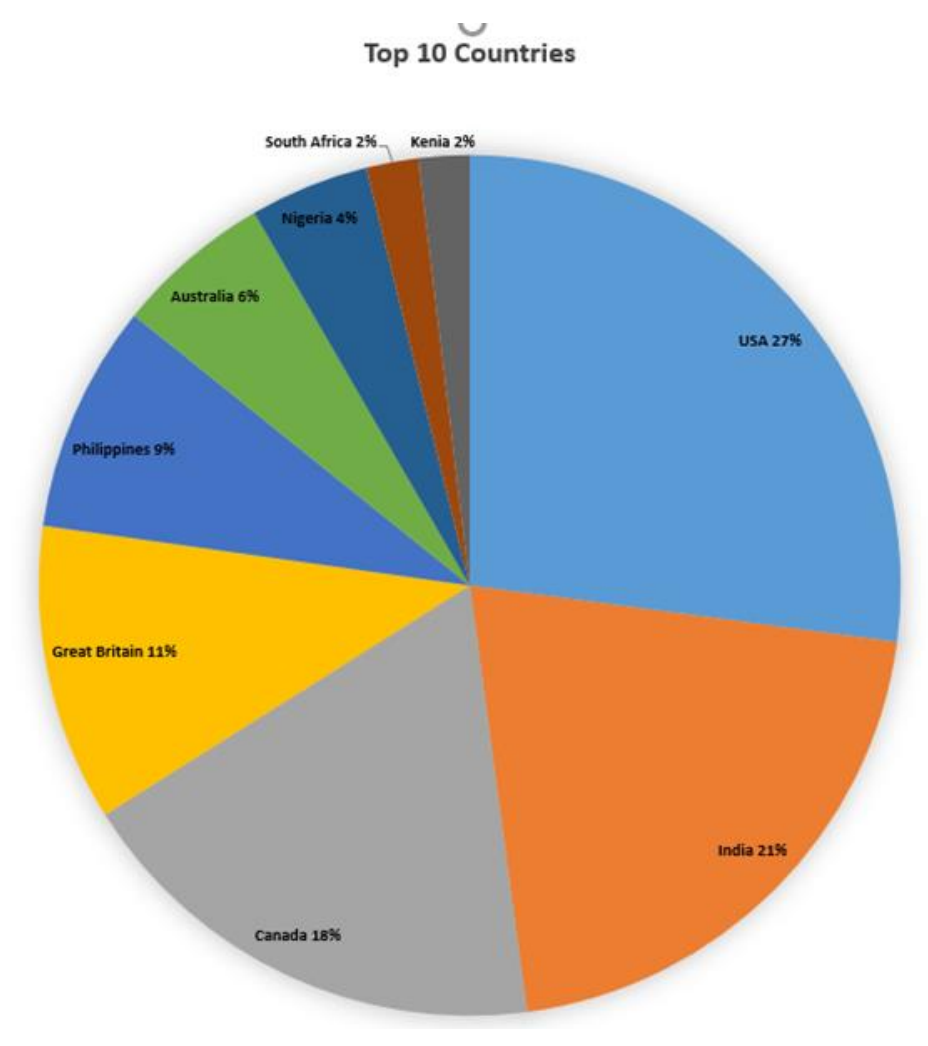

Figure 6: Top Ten Countries

Fig. 6: Page administrators from the top 10 countries of origin

When creating pages and groups, administrators can assign the pages to specific categories (Fig. 7) in order for members or followers to find them. There were a total of 180 unique categories with "Gym" (6028) had the most posts, followed by "Media News Companies" (2747) and "Health Site" (2742) posting the second and third most posts in a 12-month period. 


\section{Figure 7: Top 10 Page Categories}

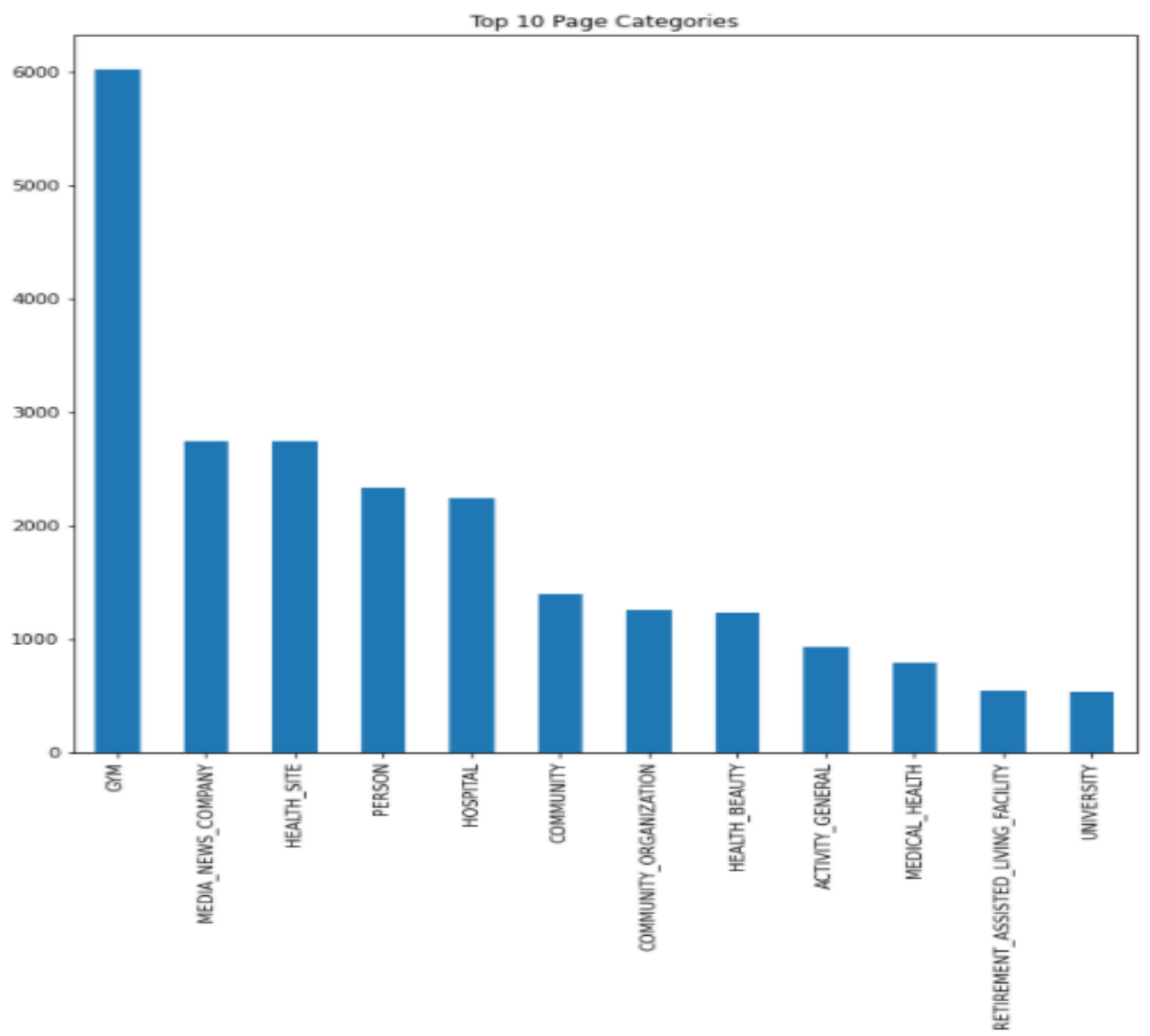

Fig 7: Representation of top 12 Page Categories on Facebook Pages and Groups

\section{Page Names:}

A total of 10, 769 unique page names occurred in a 12-month period, indicating that several pages posted more than once. The top 3 pages or groups posted 779, 545 and 261 times respectively. In most cases, the page name had the word "Health" in it as displayed Fig.8 below. 
Figure 8: Page Names

\section{Wordcloud(Page Name)}

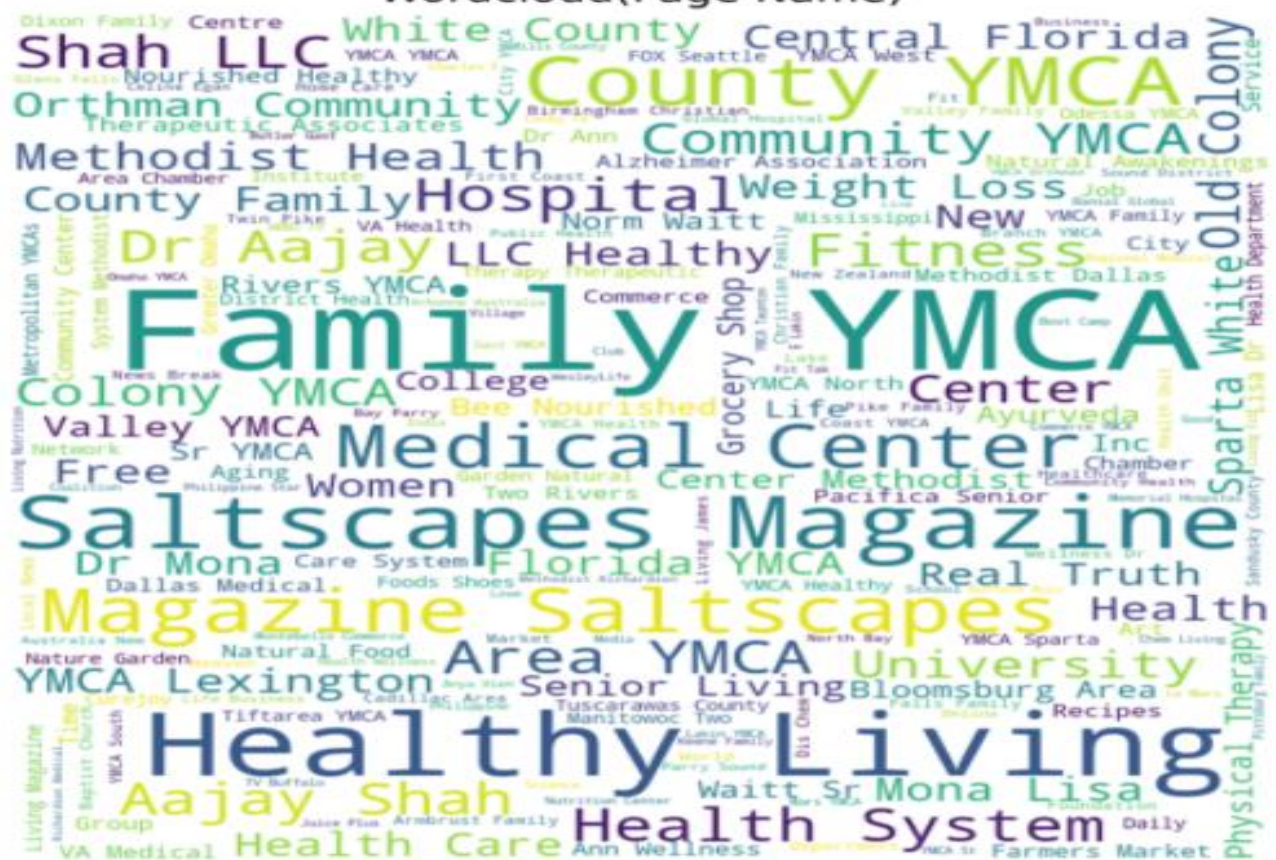

Fig.8: Wordcloud representation of Page Names of Facebook Pages and Groups

\section{Categorical analysis}

Information was ordered according to the top 12 Page Categories, namely: 'HEALTH_SITE','HOSPITAL','GYM', 'UNIVERSITY', 'RETIREMENT_ASSISTED_LIVING_FACILITY', 'MEDICAL_HEALTH', 'ACTIVITY_GENERAL', 'HEALTH_BEAUTY', 'COMMUNITY_ORGANIZATION', 'COMMUNITY', 'PERSON', 'HEALTH_SITE','MEDIA_NEWS_COMPANY' as depicted in Fig.9 below.

\section{Figure 9}

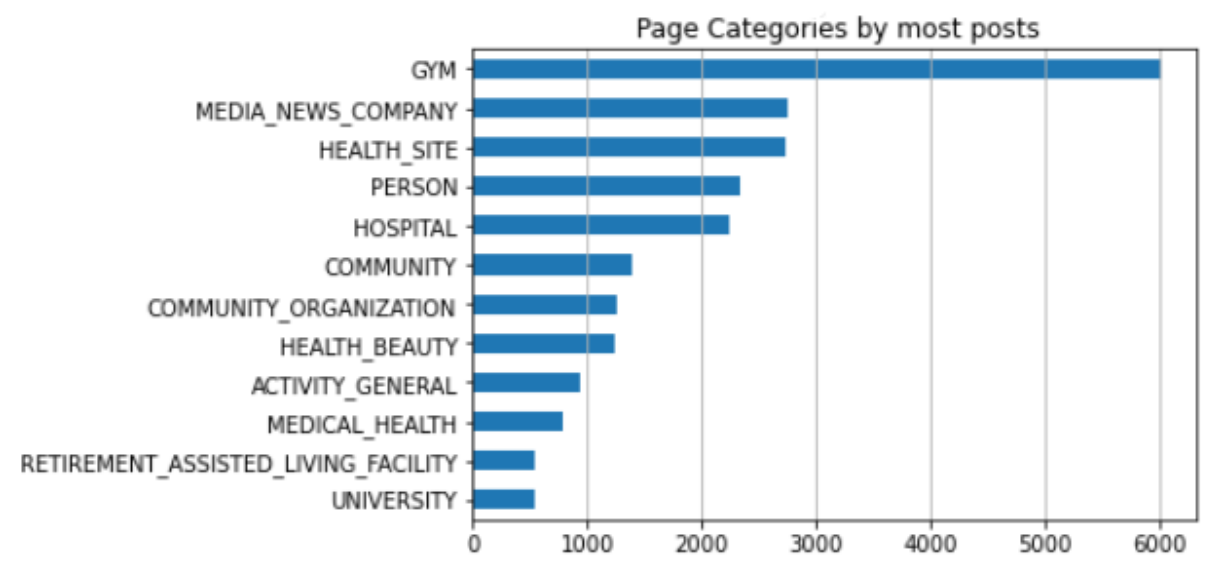

Fig. 9: Graphical representation of most posts per Page Category 
The "messages" retrieved were analysed using Natural Language Processes in Python, using TextBlob and took 1.9 seconds to run. Messages were analysed for word, character, and sentence count as well as average word and sentence length and depicted in Table 2 below.

Table 2: Summary of Descriptive Analysis of Messages

\begin{tabular}{|c|c|c|c|c|c|}
\hline $\mathbf{I D}$ & Message & $\begin{array}{l}\text { Po- } \\
\text { larity }\end{array}$ & $\begin{array}{l}\text { Mes- } \\
\text { sage } \\
\text { length }\end{array}$ & $\begin{array}{l}\text { Word } \\
\text { Count }\end{array}$ & $\begin{array}{l}\text { Average } \\
\text { Word } \\
\text { Length }\end{array}$ \\
\hline 0 & Area Agency on Aging is providing Healthy Livi... & 0,50 & 158 & 19 & 7,37 \\
\hline 2 & Aging \& Long Term Care of Eastern Washington i... & 0,35 & 468 & 71 & 5,61 \\
\hline 3 & Come join the New Womens Movement. Also, leave... & 0,14 & 132 & 27 & 3,93 \\
\hline 4 & Reishi can help slow your aging, boost your im... & $-0,30$ & 392 & 32 & 11,28 \\
\hline 7 & ??????BUZZY BEE?????? Healthy Living?Try our P... & 0,23 & 503 & 68 & 6,41 \\
\hline 8 & Today kicks off our Active Aging Week! Join us... & 0,50 & 677 & 116 & 4,84 \\
\hline 9 & Plan for healthy living! ?? Learn about the la... & 0,54 & 286 & 27 & 9,63 \\
\hline 10 & Call now to reserve your space in this helpful... & 0,50 & 431 & 69 & 5,26 \\
\hline 11 & Join us this week for a free webinar to learn ... & 0,35 & 286 & 47 & 5,11 \\
\hline 12 & Did you catch the latest edition of our newsle... & 0,24 & 1172 & 107 & 9,96 \\
\hline
\end{tabular}

Table 2: Examples of messages, Sentiment Polarity, message length, word length and average word length.

Messages were analysed for sentiment and polarity. Posts regarding aging and health were overwhelmingly in the mean positive sentiment at 0.27 . Mean message length was at 650 characters with a minimum of 2 to maximum of 5660 . Posts with status updates and photos, videos and links with descriptions contained a minimum of 1 word, maximum of 1 038 with a mean of 98,12 .

Figure 10: Message Sentiment Polarity 


\section{Message Sentiment Polarity}

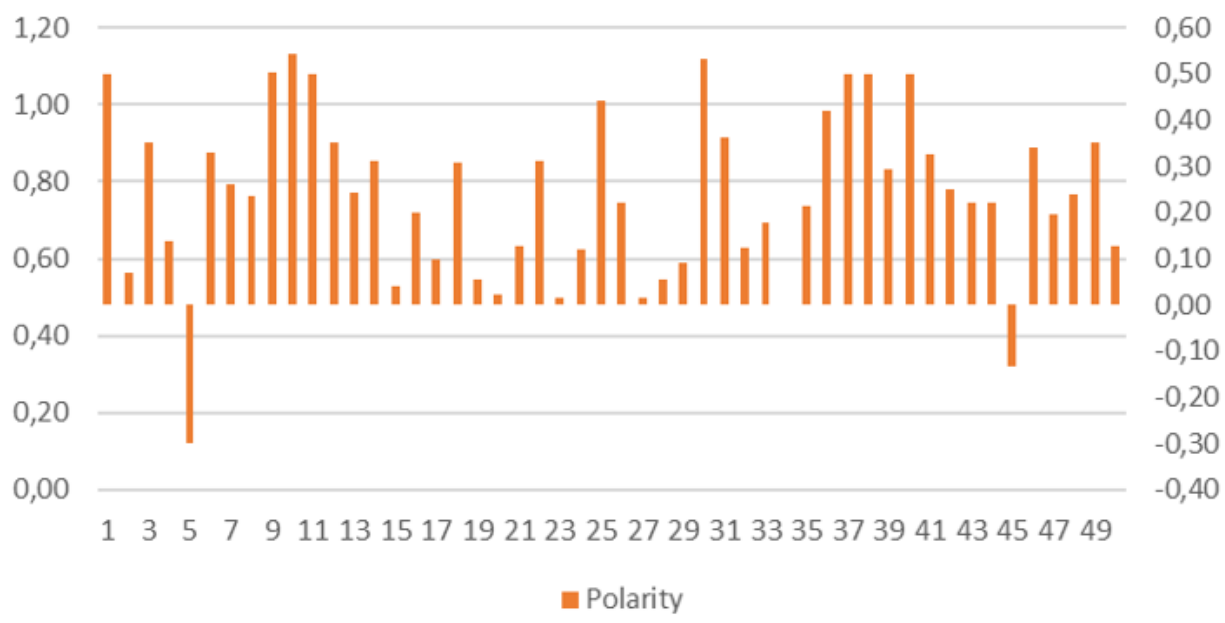

Figure 10: Visualisation of sentiment polarity of messages.

Word embedding or vectorising is an important tool to understand context of words in NLP [20]. The concept refers to the meaning of words in relation to their distribution in the text. In the drawing (Fig. 11), the word being investigated in represented by a red dot and relates to other words in how close they are in the grammatical environment. Representations of input words form an important part of NLP research [20]. In the example below, word "health" appeared in both the top Bigram and Trigram words. The word vector represents probability distributions of the word "health".

\section{Figure 11: Health: Probability Analysis}

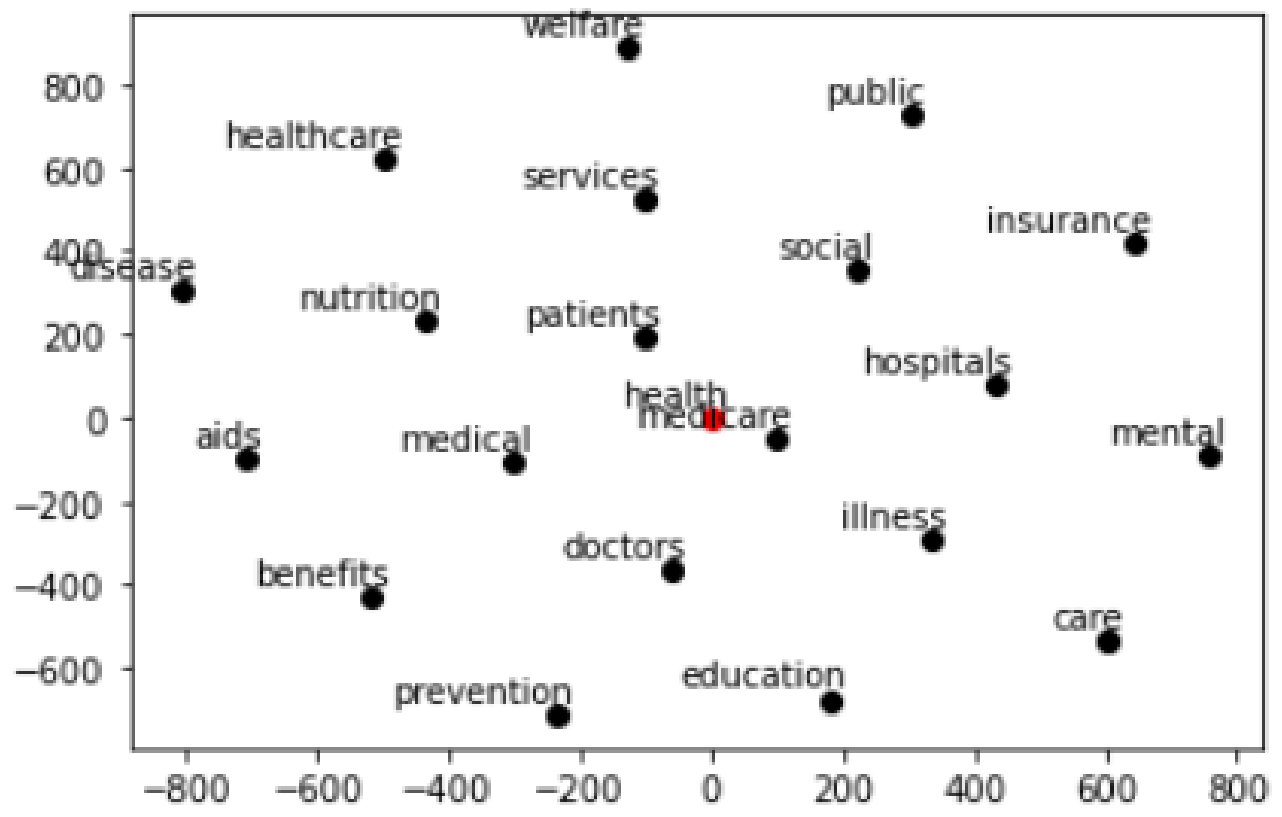

Figure 11: schematic representation of probability distribution of the word "health" which is represented by a "red" dot in the drawing above.

\section{Discussion}


Two datasets were investigated to identify any relation between social media health posts and the various COVID-19 new infections and or new deaths over a 12-month period. The relation, as depicted in Graph 1 between daily new infections and daily new deaths have been identified in numerous research, and thus corroborates this trend [22-25].

A pivotal note, is that the amount of "Likes at Posting" (and even "Total Positive") is consistently higher than the amount of "Shares" and one would assume that if someone "liked" a post, they would want to disseminate that information. Keeping in mind instances of "echo-chambers" [11] and "emotional blunting [10], Fig. 2 indicates Facebook reactions responding to the peaks and valleys of the infection rates, except in one instance in Aug 2021. The content of the posts were not investigated.

The positive trend-line in positive reactions could possibly be attributed to resilience strategies, by re-engaging in past activities that used to bring joy such as exercising. Increased emphasis was placed on the importance of physical health and by implication, mental health [24, 25]. To promote healthy behaviour, Pages and Groups employed several strategies, such as 'getting out of your fans' way [28], sharing expertise through texts and visual posts. The health pages and groups in the sample, focused on positive posts to improve physical health (Fig. 3 and Fig 10).

Evidence in Fig. 3 indicate an increase in positive reactions and the decline in negative comments within the period of a year. Founded on various studies, $[10,11]$ this may be attributed to a blunting- or desensitization effect. More realistically, it may be attributed to a more general concern for physical and mental well-being [24], and therefore an increased awareness of healthy ways of living.

Fig. 4 shows a rise in social engagement on Facebook Pages and Groups while Facebook reported a steady increase in users for the same period [29]. According to Dykes, [17], social media is used more and more to disseminate information and driving change [28]. In this 2021 study, Osuwu-Ansah et al., [30] also claims that groups and pages serve the "purpose of information-sharing, peer-tutoring, learning and finding friends" (p.7), but also states that social media competence can be a hindrance. Older generations might use Facebook to "learn" from only and "share" rather than comment or voice their opinion.

Most posts (Fig. 5) on aging and health were photographs and the second most posts were links. Photographs are one of the most popular features on Facebook. Personal photos can be shared, tagged and at times have their own comment sections, which allows for conversation. Often campaigns encourage followers that tag or share photos [28]. It is relatively easier to share an existing post than to "make up" new text posts, which could be explained by the "echo-chamber" phenomenon [11]. the extent to which followers engage with posts and is not within the scope of this research remains debatable.

As can be expected, 27\% (Fig. 6) of the pages and groups that posted on health and aging, have their administrators originate from the United States of America. Northern America is purported to have the third largest population use of the Internet [31] of which the USA and China are the highest users of social media with a reported $71,5 \%$ Facebook subscribers in the USA [32].

The majority of categories that pages belong to institutions or companies that promote health. People who search for health information would be drawn to these categories and pages with "health" in the name.

Most page or groups names in Fig. 8 have the word or stems of the words "health", or "family" in the name, as depicted in the Wordcloud. Names of groups or pages reflect 
the content therefore and will rank higher on a search item. It therefore stands to reason, that the pages or groups will have similar names.

Although thematical analysis was not in the scope of this study, a cursory categorical analysis revealed that pages in the Gym category (Fig. 9) included the most posts on healthy aging or aimed at older members.

Healthy living or actions that would improve your health, in essence is a positive sentiment. This is corroborated by the majority posts (Table 2 and Fig. 10) with a positive sentiment.

As can be seen in Fig. 11, words such as welfare, services, patients, doctors, prevention, medicare, education, social, etc, are used either before or after the word "health" on the post mentions. Much emphasis is placed on "aids", "benefits", "prevention", "nutrition", "social" etc. in the words used on Facebook.

There were several limitations to the study. It was not the aim of the researcher to prove credibility of information on the various social media sites, but rather to investigate how and to what extend information was disseminated. The "Types" of posts, such as "Photos" or "Videos" were not investigated and only "Statuses" were analysed and would be interesting in future studies. This provides leeway for further training in digital data analysis and more in-depth thematic analyses. The focus of the study was not on the influence of COVID-19 posts, but statuses that focused on health during the specific COVID period.

Specific thematic analysis was not in the scope of this research and therefore peaksand-valley incidents cannot be explained. The content of the posts were not analysed and provides scope for further studies. Pathological use and rumination on health conditions were not investigated and does not form part of this study.

\section{Conclusions}

This study attempted to visualize data obtained from Facebook through CrowdTangle. It tried to show links between status updates during the COVID-19 pandemic and health information seeking behaviour in older generations. It also looked at using simple coding to make this analysis and how it would present information. It appears as if positive information seeking behaviour increased during lockdown periods. This information can have an effect on how information is disseminated in future. Social media does not seem to be the sole playground of the young and the youthful.

Supplementary Materials: The following are available online at www.mdpi.com/xxx/s1, Figure S1: title, Table S1: title, Video S1: title.

Author Contributions: For research articles with several authors, a short paragraph specifying their individual contributions must be provided. The following statements should be used "Conceptualization, C.H.; methodology, C.H.; software, C.H.; validation, M.G.; formal analysis, C.H.; investigation, C.H.; resources, C.H.; data curation, C.H.; writing - original draft preparation, C.H.; writingreview and editing, M.G.; visualization, C.H; project administration, C.H. All authors have read and agreed to the published version of the manuscript."

Funding: This research received no external funding.

Institutional Review Board Statement: The study was conducted according to the guidelines of the Declaration of Helsinki, and approved by the Institutional Ethics Committee of UNIVERSITY OF ZULULAND (UZREC 171110-030 Dept. 2021/1).

Informed Consent Statement: Not applicable. 
Data Availability Statement: Datasets are available in a public repository at https://data.mendeley.com/drafts/2ynzd8ywcz?folder=0da6c569-15fc-4e3e-b62b-77a62e930451.

Acknowledgments: NW Hermann for teaching and verifying coding.

Conflicts of Interest: The authors declare no conflict of interest.

\section{References}

(1) Freberg, K. Social Media for Strategic Communication: Creative Strategies and Research-Based Applications; Sage Publications Ltd: Thousand Oaks, Califormia, 2019.

(2) Kingwell, M. Social Media and Your Brain: Web-Based Communication Is Changing How We Think and Express Ourselves; Prado, C. G., Ed.; Praeger: Santa Barbara, 2017.

(3) Freberg, K. Social Media. In The Sage Encyclopedia for Corporate Reputation; Carroll, C. E., Ed.; SAGE Publications Inc.: New York, 2016; pp 773-776.

(4) Fraser, L. What data is CrowdTangle tracking? https://help.crowdtangle.com/en/articles/1140930-what-data-is-crowdtangletracking (accessed Nov 21, 2021).

(5) McFarlane, L. Prices Paid for Social Media Use. In Social Media and your Brain: Web-based Communication is changing how we think and express ourselves; Prado, C. G., Ed.; Praeger: Santa Barbara, 2017; pp 119-132.

(6) Leitch, A. Exclusive Spaces. In Social Media and your Brain: Web-based Communication is changing how we think and express ourselves; Prado, C. G., Ed.; Praeger: Santa Barbara, 2017; pp 89-104.

(7) Mochon, D.; Johnson, K.; Schwartz, J.; Ariely, D. What Are Likes Worth? A Facebook Page Field Experiment. J. Mark. Res. 2017, 54 (2), 306-317. https://doi.org/10.1509/jmr.15.0409.

(8) Kaspar, K.; Müller-Jensen, M. Information Seeking Behavior on Facebook: The Role of Censorship Endorsement and Personality. Curr. Psychol. 2021, 40 (8), 3848-3859. https://doi.org/10.1007/s12144-019-00316-8.

(9) La France, A. Dispatches: Facebookland. The Atlantic Monthly Group. 2021, pp 18-20.

(10) Lee, K.; Lee, B.; Oh, W. Thumbs up, Sales up? The Contingent Effect of Facebook Likes on Sales Performance in Social Commerce. J. Manag. Inf. Syst. 2015, 32 (4), 109-143. https://doi.org/10.1080/07421222.2015.1138372.

(11) Praet, S.; Van Aelst, P.; van Erkel, P.; Van der Veeken, S.; Martens, D. Predictive Modeling to Study Lifestyle Politics with Facebook Likes. EPJ Data Sci. 2021, 10 (1). https://doi.org/10.1140/epjds/s13688-021-00305-7.

(12) Kozinets, R. V. Netnography Mobilized. In Netnography Unlimited: understanding technoculture using qualitative social media research; Kozinets, R.V, \& Gambetti, R., Ed.; Routledge: New York, 2021.

(13) Kozinets, R. V. Netnography: Doing Ethnographic Research Online, 2nd ed.; Sage Publications: Los Angeles, 2010.

(14) Ajogwu, A.; Odeyemi, K. Active Ageing: Process and Determinants among Middle-Aged Men in Rural and Urban Communities in Lagos State, Nigeria. Pan Afr. Med. J. 2021, 39. https://doi.org/10.11604/pamj.2021.39.195.27546.

(15) Tebé, C.; Valls, J.; Satorra, P.; Tobías, A. COVID19-World: A Shiny Application to Perform Comprehensive Country-Specific Data Visualization for SARS-CoV-2 Epidemic. BMC Med. Res. Methodol. 2020, 20 (1). https://doi.org/10.1186/s12874-020-011219.

(16) Perlman, S. E. Use and Visualization of Electronic Health Record Data to Advance Public Health. American Journal of Public Health. American Public Health Association Inc. February 1, 2021, pp 180-182. https://doi.org/10.2105/AJPH.2020.306073.

(17) Dykes, B. Effective Data Storytelling: How to Drive Change with Data, Marrative and Visuals; John Wiley \& Sons, Inc: New Jersey, 2020.

(18) Dong, E.; Du, H.; Gardner, L. An Interactive Web-Based Dashboard to Track COVID-19 in Real Time. The Lancet Infectious Diseases. Lancet Publishing Group May 1, 2020, pp 533-534. https://doi.org/10.1016/S1473-3099(20)30120-1.

(19) CrowdTangle. Citing CrowdTangle Data. CrowdTangle Team. Facebook, Menlo Parl, California, United States 2021. 
(20) Jurafsky, D.; Martin, J. H. Speech and Language Processing: An Introduction to Natural Language Processing - Draft; 2022.

(21) Murthy, D. The Ontology of Tweets: Mixed Method Approaches to the Study of Twitter. In The SAGE Handbook of Social Media Research Methods; Sloan, L., Quan-Haase, A., Eds.; Sage Reference: London, 2017; p 559.

(22) Khan, F.; Ali, S.; Saeed, A.; Kumar, R.; Khan, A. W. Forecasting Daily New Infections, Deaths and Recovery Cases Due to COVID-19 in Pakistan by Using Bayesian Dynamic Linear Models. PLoS One 2021, 16 (6 June), 1-15. https://doi.org/10.1371/journal.pone.0253367.

(23) Pavan Kumar, S. T.; Lahiri, B.; Alvarado, R. Multiple Change Point Estimation of Trends in Covid-19 Infections and Deaths in India as Compared with WHO Regions. Spat. Stat. 2021. https://doi.org/10.1016/j.spasta.2021.100538.

(24) Oki, K. Does CAGE Framework Predict COVID-19 Infection? Ann. Bus. Adm. Sci. 2020, 19 (5), 175-192. https://doi.org/10.7880/abas.0200721a.

(25) Ephrem, B. G.; Appaadurai, S. G.; Dhanasekaran, B. R. Analysis of COVID-19 Infections in GCC Countries to Identify the Indicators Correlating the Number of Cases and Deaths. PSU Res. Rev. 2021, 5 (1), 54-67. https://doi.org/10.1108/prr-08-20200027.

(26) Fossati, C.; Torre, G.; Vasta, S.; Giombini, A.; Quaranta, F.; Papalia, R.; Pigozzi, F. Physical Exercise and Mental Health: The Routes of a Reciprocal Relation. Int. J. Environ. Res. Public Health 2021, 18 (23). https://doi.org/10.3390/ijerph182312364.

(27) Dhawan, N. Coping Mechanism To Manage Stress: An Empirical Analysis. Delhi Bus. Rev. 2017, 18 (2), 87-96.

(28) Zarrella, D. The Social Media Marketing Book; Ruma, L. R. T., Ed.; O’Reilley Media: Beijing, 2010.

(29) Statista https://www.statista.com/statistics/264810/number-of-monthly-active-facebook-users-worldwide/ (accessed Jan 18, 2022).

(30) Owusu-Ansah, C. M.; Arthur, B.; Yebowaah, F. A.; Amoako, K. The Use of Social Media among First-Year Student Groups: A Uses and The Use of Social Media among First-Year Student Groups: A Uses and Gratifications Perspective. 2021, 11 (September), 7-34.

(31) Johnson, J. Countries with the highest number of internet users 2021 https://www.statista.com/statistics/262966/number-ofinternet-users-in-selected-countries/ (accessed Jan 10, 2021).

(32) Internet World Stats https://www.internetworldstats.com/unitedstates.htm (accessed Jan 10, 2022). 